\title{
MULTITEMPORAL SAR INTERFEROMETRY IN THE MESSOLONGHI-ETOLIKO NATURA 2000 OVERLAPPING DELTAS AREA
}

\author{
Gkartzou E. (1) , Parcharidis I. ${ }^{(2)}$, Karymbalis E. ${ }^{(3)}$, Drakatou M.L. ${ }^{(4)}$ \\ Harokopio University of Athens, Department of Geography, El. Venizelou 70, 17671 Athens, Greece \\ (1) gkartzou@hua.gr, ${ }^{(2)}$ parchar@hua.gr, ${ }^{(3)}$ karymba@hua.gr, ${ }^{(4)}$ mldrakatou@gmail.com
}

\begin{abstract}
This paper can be considered as the beginning of a project approaching through the reliable and precise techniques of interferometry the risk of an upcoming coastal downgrading and even a possible socioeconomic destruction of a deltaic area. The study area is located in the north part of the Gulf of Patras in the central west coast of Greece. It is extended between the Acheloos and Evinos rivers and protected by the Ramsar Convention while is included in the Natura 2000 network. It is one of the most important areas for both environmental and financial reasons. The aim of this research is the estimation of ground deformation at the broader overlapping deltaic area of Evinos and Acheloos rivers, by implementing a "hybrid INSAR" methodology and the Persistent Scatterers Interferometry Technique (PSInSAR). Our results revealed negative values of deformation with a maximum rate of deformation locally to the nonmountainous areas up to $-12 \mathrm{~mm}$ along the Line Of Sight.
\end{abstract}

Key words: SAR interferometry, SVD, PSI, ground deformation, subsidence, Messolonghi, Greece.

\section{INTRODUCTION}

The purpose of this study is to monitor the ground deformation of the deltaic - lagoonal systems created by Acheloos and Evinos rivers (Western Greece) using a "hybrid INSAR" methodology with elements of conventional DINSAR, multi-baseline interferometry approaches and the PSI technique, which belongs to the recent advances in SAR interferometry methods that further improve accuracy of measurements by overcoming problems such as atmospheric or orbital distortions. Anthropogenic activities affecting the dynamic of the complicated natural system will be also considered, as well as threats related to sea level rise.

The Messolonghi-Etoliko region is located about 250 $\mathrm{km}$ northwest from Athens, the capital of the Greek Republic (Fig.2). The latitude and longitude of the study area are $38 \circ 26$ and $21 \circ 21$ respectively and can be characterized as flat area with an altitude of 6 meters defined by the mouth of Evinos River to the mouth of Acheloos River. Between the deltaic plains of the two rivers, complicated lagoonal systems are formed (Etoliko lagoon, Messolonghi lagoon, Klisova lagoon). The region is a complex system dominated by the Messolonghi lagoon complex (Fig.1), located in the central part of the system of wetlands and occupying an area of 11.200 ha (Wikipedia). Famed for her beauty and her natural resources, the big lagoon of Messolonghi Etoliko constitutes with the Delta of rivers Acheloos and Evinos one of the bigger and most important water biotopes of Mediterranean. This very beautiful place, that has been declared National Park, is a cluster of water biotopes where sweet marshes and salty marshes vary, mudflats, aquatic forests, dunes, lane islands and salty meadows. Around them they erect their volume Varasovas and Arakynthos, as the gorge of Kleisoura. The whole region is part of the Natura 2000 (GR2310002) and protected wetland under the Ramsar Convention.

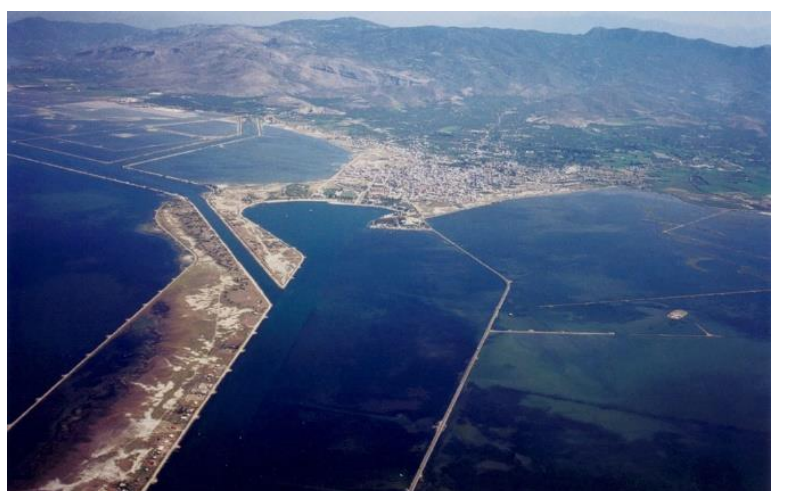

Figure 1: Aerophotography of the study area

The Messolonghi lagoon complex is placed behind a dotted sandy coastal strip, located between the estuary of the Evinos River and Koutsilaris hill and is connected to the Gulf of Patras through a large opening. In the eastern part of the Messolonghi plain is the delta of Evinos and in the western part of the region is the Acheloos delta. The largest part of the plain was formed by deposits of these two rivers. The depositional environment of the western river system (Acheloos) exhibits several islands - like bedrock hills, which rise out of the deltaic plain, from which higher is the Koutsilaris (433 m). In the same area, some former beds of Acheloos are distinguished. The Acheloos River flows nowadays into the sea forming meandering channels, which are related to different evolution stages 
of the depositional formation of the deltaic plain. Due to the longshore sand transport caused by the SW winds and the predominant wave regime, large barrier beach systems are formed, which separate the subsided parts of the deltaic plain from the open sea and form shallow lagoons. River Acheloos has deteriorated significantly due to two basic reasons, the river flow is completely controlled by humans and follows different rates than the physical. Also the dams along the river bed have diminished the sediment deposits.

Similar but in smaller space scale is the evolution of Evinos deltaic system. The estuary of Evinos extending from the east coast of Kleisova to the base of Varasovas.
Evinos does not have a continuous flow throughout the year and in the coastal zone, which extends from the eastern shore of Kleisova to the west of the mouth of Evinos, the ground is below sea level and the drainage is inhibited resulting flooding due to rainfalls.

The dynamic of the complicated deltaic-lagoonal systems is influenced by anthropogenic activities. Water extraction from the river channels, river bed, and river mouth deviations and canalizations, have changed the dynamics of the river's discharge systems leading to erosional procedures, threatening the sand barriers and the lagoonal systems. The same sensitive coastal systems are threatened from sea level rise.

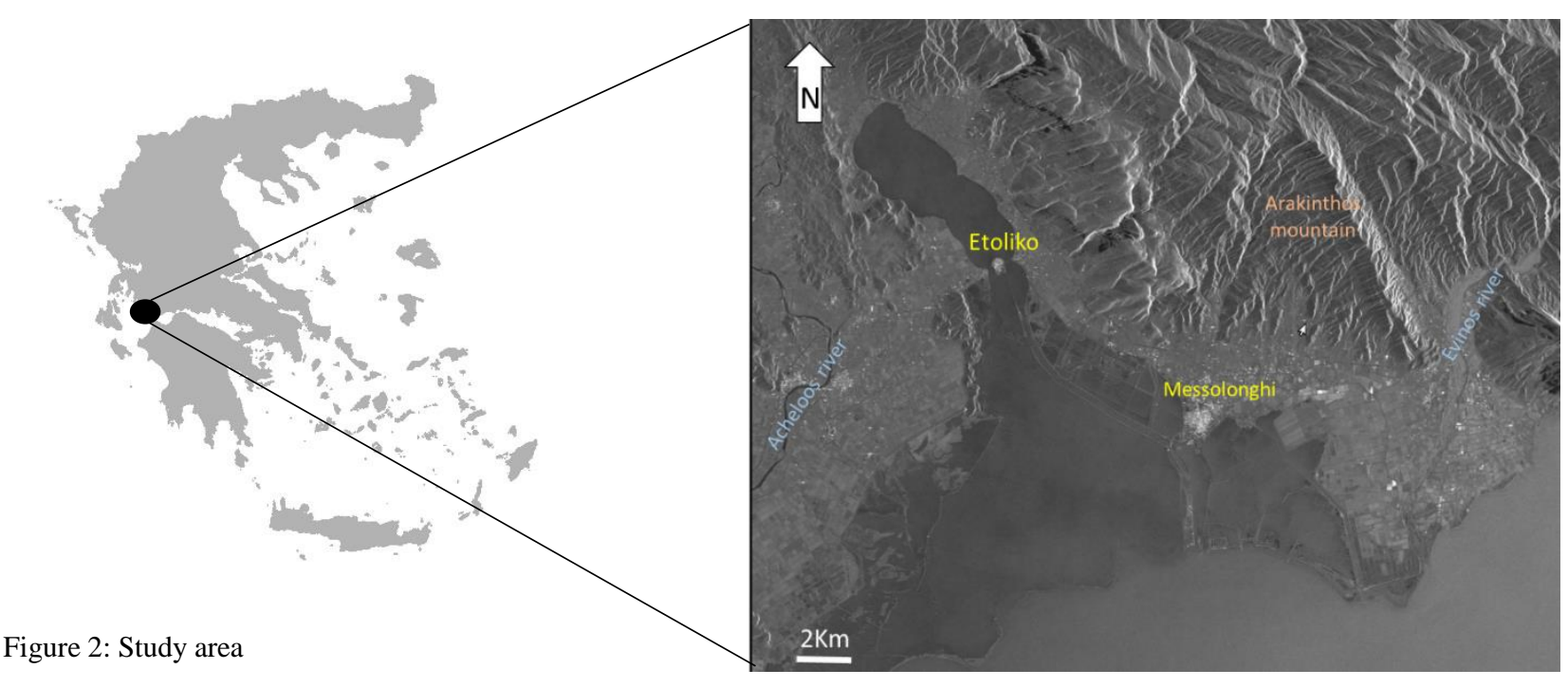

\section{GEOMORPHOLOGY-GEOLOGY OF THE STUDY AREA}

In the lowlands of the study area, the terrain is almost flat. These areas are either bare or cultivated. Some parts are swamps an intermediate stage between the terrestrial and the lagoons. Another part is covered by saline soils which have emerged during the desiccation of some swamps. A special and very important morphological element is the creation and existence of small sandy islands in the outer part of the lagoons and the formation of sand strips. The creation of those sand strips is a result from the alluvial processes and play an important protective role for the area. The hydrographic network is relatively dense and is mostly manmade, as long as most streams that descend from Mount Arakinthos, are diverted to the system of irrigation canals of the region. According to the above, the main creators of the current version of the lowland areas of Messolonghi are above the tectonic events, the rivers Acheloos and Evinos with their alluvial activities. The mountainous part of the study area consists of the mount Arakinthos composed of Palaeogene limestones, the basin of the river Evinos as well as the mountains to the west of the Etoliko lagoon and belong to the southern part of the Pindos mountain range. The water catchment of the Evinos River is mostly mountainous, with intense relief and surrounded by the mountains Panaitoliko, Vardoussia, Arakinthos and Nafpaktias, while to the south, near the delta, the relief becomes smoother with slopes of around $5 \%$.

The study area lies within the Ionian Zone of the West Hellenic Nappe of the External Hellenides [25]. During the Miocene, tectonic activity shifted to the Hellenic arc which extends from Ionian Islands in the west, passing Crete in the south to the island of Rhodes in the east [3], [17]. Aetolias mountainous hinterland is opposed to the shallow coastal plain shaping its southwestern most fringe. Ongoing delta progradation by the Acheloos and Evinos, both originating in the southern Pindos Mountains, resulted in silting up of the shelf region of the Gulf of Patras forming a large, overlapping delta [23]. The petrography of the overlapping delta reflects the bedrock. The sand fraction of both deltas is predominantly composed of carbonate, chert and quartz 
whereas feldspar, heavy minerals play a secondary role. The fine fraction is dominated by montmorillonite, illite and poorly crystallized chlorite while calcite quartz and feldspar are a minor constituent [16].

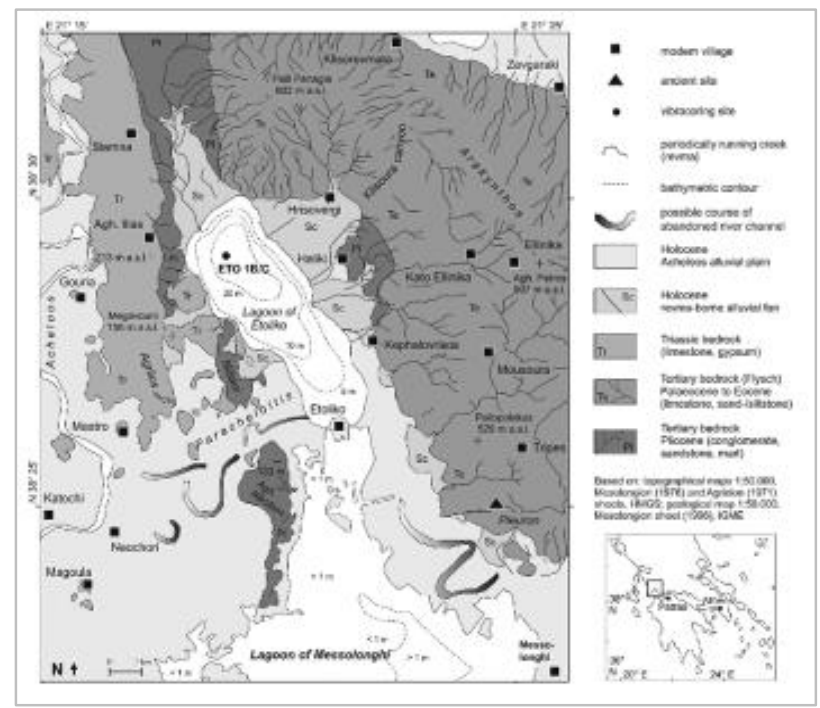

Figure 3: Simplified geological Map of the study area. (Source: E. Haenssler et al. / Quaternary International 308309 (2013) 89 e104)

\section{CLIMATE}

Characterized by a high seasonality with hot, dry summers and mild, wet winters, recent climate in the study area reflects the outlined large scale circulations patterns. The average annual temperature ranges from 17 to $180 \mathrm{C}$ with an annual thermometric width range from 18 to $19 \mathrm{oC}$. The region experiences high spatial and temporal variability of rainfall additionally controlled by sharp hydrological gradients resulting from high relief differences with approximation to the mountainous interior. Hence, rivers and creeks originating in the mountains strongly reflect humid mountain climate which may trigger distinct flood events and the reactivation of ancient river channels [27]. The average annual rainfall is around 800-1000 mm with most rainy period from November to February. The rainfall occurs during the months October to April, resulting in a 4.5-month dry season (May-September). The average annual relative humidity ranges from $64-$ $68 \%$ in both coastal zone (meteorological station Technological Institute of Messolonghi), and within the county, mainly because of large bodies of water. During the summer months (dry season) prevailing westerly winds, while all the other months mostly south southwestern and north - northwestern. Rarely appear in the area eastern winds, mainly because of the mountain range of Pindos, which forms a natural boundary to the east of the prefecture [28].

\section{DATA USED AND METHODOLOGY}

Covering the periods between 1994 and 2001 ( $~ 7 \mathrm{yr}$ ) and 2002-2010( 8 yr), a total number of 33 ERS-1\&2 and 21 ENVISAT ASAR scenes acquired along the ascending track 186 and 43 ERS-1 \& 2 and 27 ENVISAT ASAR scenes acquired along the descending track 50, and were processed using the GAMMA software. All data were obtained by the European Space Agency (ESA). The selection and order of the images were made by EOLi software (http://earth.esa.int/EOLi.html). Initial estimations of the interferometric baselines were calculated from the Deflt precise orbit state vectors. The topographic phase was simulated based on SRTM V3 DEM of approximate spatial resolution of $90 \mathrm{~m}$. The basic processing steps applied to the whole data set include the conversion of raw data to SLC while updating their parametric files with the orbit data, co-registration and cropping of SLCs, simulation of the topographic phase, generation of differential interferograms, filtering and phase unwrapping. The data obtained were processed using two different techniques, the Persistent Scatterers Interferometry Technique (PSInSAR) and the DInSAR technique with the application of an SVD (Singular Value Decomposition) method.

\section{SUBSIDENCE ESTIMATION USING THE PERSISTENT SCATTERERS INTERFEROMETRY TECHNIQUE}

By the end of the 1990s various groups were looking at ways of addressing the limitations of conventional InSAR by processing multiple acquisitions in time. One approach involves identifying 'persistent scatterer' pixels, whose scattering characteristics remain stable in time and when viewed from different angles [6]. The PS approach is optimized for resolution cells containing a single point scatterer [15]. Persistent Scatterer Interferometry (PSI) distinguishes itself from other SAR interferometric processings by using a single master image to generate a stack of differential interferograms without limitations in temporal or spatial baselines. PS candidates are selected based on their backscattering properties. On these points, the PS approach adopts essentially a model-based, temporal unwrapping strategy. Accordingly, a priori information on the displacement is necessary, from which a deformation model can be established. In general, the average linear displacement velocity and the DEM error are considered as the two major parameters of 2D linear regression of the wrapped phases.

The differential interferometric methodology that will be used in this study is the PSI based on the Interferometric Point Target Analysis (IPTA) algorithm 
included in GAMMA software. This advanced multitemporal approach called the Persistent Scatterers (PS) technique was introduced by Ferretti, the first team who defined this technique to measure and monitor ground deformation by millimetric precision, achieves values of 1-3 $\mathrm{mm}$ on individual measurements and $0.1-0.5$ $\mathrm{mm} /$ year on the average deformation rate. According to the description of the PS technique based on Colesanti et al., Ferretti et al. [4] [6], the key processing steps of the PS technique are firstly the computation of the interferograms, then the computation of the differential interferograms using a digital elevation model, the preliminary estimation of the presumably most coherent pixel and finally the refinement of the third step; the coarse grid of PS candidates estimate the long wavelength part of the atmospheric signal. After interpolation of these estimates, the differential interferograms are corrected, and additional PSs are computed [6], [9], [14].

Therefore, in order to produce the interferograms, IPTA methodology requires one reference scene in the middle of the time frame of our data set with low atmospheric distortions and also the produced interferometric pairs to have a minimum baseline (Bp). For the ERS ascending dataset the best suitable scene was August 25, 1996, with an average $\mathrm{Bp}$ of $400 \mathrm{~m}$ and for the ERS descending dataset was December 19, 1997, with an average $\mathrm{Bp}$ of $373 \mathrm{~m}$. Afterwards the initial differential interferograms were produced by simulation of the unwrapped interferometric phase based on the initial baselines and the DEM. A total number of approximately 130896 and 58318 candidate points for ERS ascending and ERS descending dataset correspondingly, were determined. The spatial distribution of the candidate points is not homogeneous with high densities of PS located in built-up and.

Based on the regression analysis, the quality of the PS candidates was further evaluated through the estimated standard deviation of the phase difference and many PSs with a phase standard deviation larger than the indicated were rejected with the majority of the rejected points located over mountainous areas. The PSs were further processed in order to compensate atmospheric and noise effects. Thus, residual phases were spatially filtered by applying a low-pass spatial filter. The generated results consist of height corrections, linear deformation rates, atmospheric phase, refined baselines, temporal coherence, and nonlinear deformation histories for each scatterer. Finally the deformation phases were transformed into displacements and geocoded to the selected cartographic reference system.

\section{SUBSIDENCE ESTIMATION USING THE SINGULAR VALUE DECOMPOSITION (SVD) METHOD.}

In order to validate our results we applied a second reliable method, the Differential SAR Interferometry algorithm referred to as Small Baseline Subset technique that helps us to detect surface deformation. The basic aspect of this technique is that the data pairs used to generate the interferograms, are selected in a way to minimize the baseline between the acquisition orbits and therefore to limit the decorrelation phenomena [31]. Moreover, in order to reveal the deformation history, Singular Value Decomposition (SVD) method was implemented [2],[26]. The SVD method allow us to easily relate independent SAR acquisition data set separated by large spatial baselines, thus increasing the number of data used for the analysis of the area of interest.

For the period 1995-2001 (ERS-1\&2) perpendicular baselines up to $200 \mathrm{~m}$ and time interval up to 2 years in both ascending and descending orbit were accepted in order to form a sufficient network. On the other hand, from the period 2003 to 2010 (ENVISAT) perpendicular baselines up to $400 \mathrm{~m}$ and time interval up to 3 years in ascending orbit and $\mathrm{Bp}$ up to $350 \mathrm{~m}$ along with 2 years of temporal separation in descending orbit for each acquisition to form interferograms, were selected. Based on the above parameters were established networks, which reflected the date of receipt of each image, relative to the baseline, as well as the pairs of images which produced conventional interferograms. The figures 4 and 5 (Fig.4\&5) below depict the produced networks. The interferograms produced were further analyzed and filtered using adaptive filtering. This approach tries to increase the temporal sampling rate and to provide spatially dense deformation maps by using small baseline interferograms. The next step is related with unwrapping the adaptive interferograms using the minimum cost-flow algorithm. The threshold for the average coherence across all interferograms was set to 0.35 . The reference point was carefully selected on stable ground $9 \mathrm{Km}$ western of Etoliko, in Katochi village. This procedure was repeated using precision baselines in order to decide which interferograms are going to be selected as input to the SVD solution.

After selecting the reference point, it is applied the SVD algorithm which allows the passing from the single reference acquisitions to multiple reference ones. The produced result was a product in a raster format with the accumulated phases, which reflects the average rate of phase change per time (rad/year) and also a pixel based time series analysis. In order to visualize the values of the deformation patterns derived from the SVD solution they were geocoded to (UTM) coordinates and plotted to the DEM of the region. 

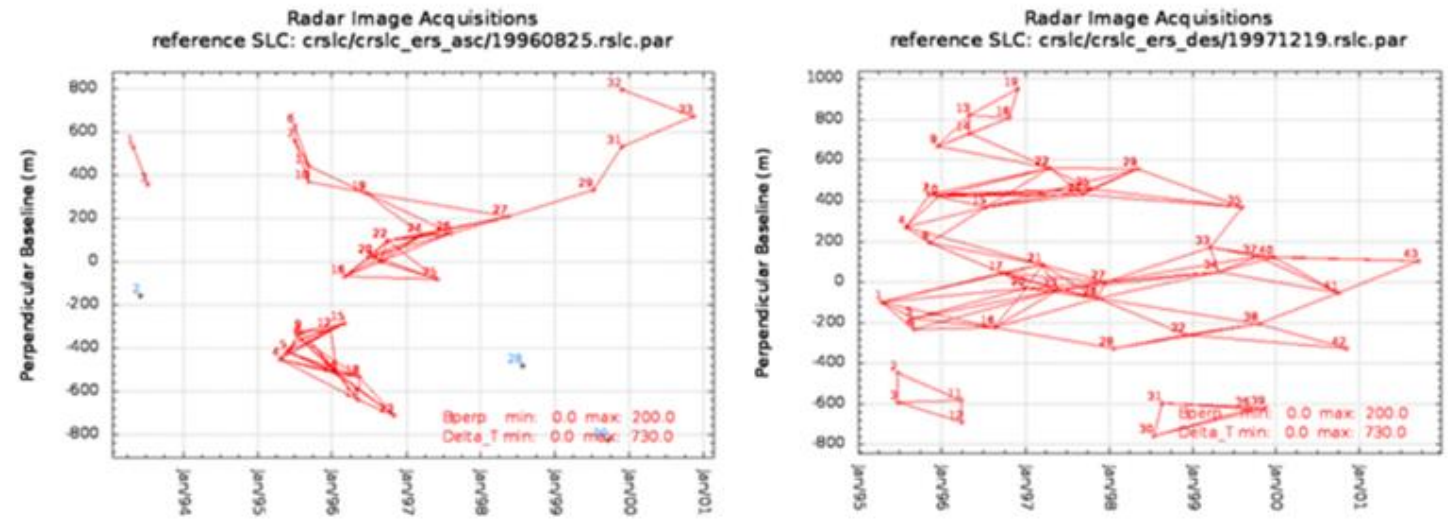

Figure 4: Network of ERS-1\&2 ascending (on the left) and descending (on the right) for the period 1994-2001
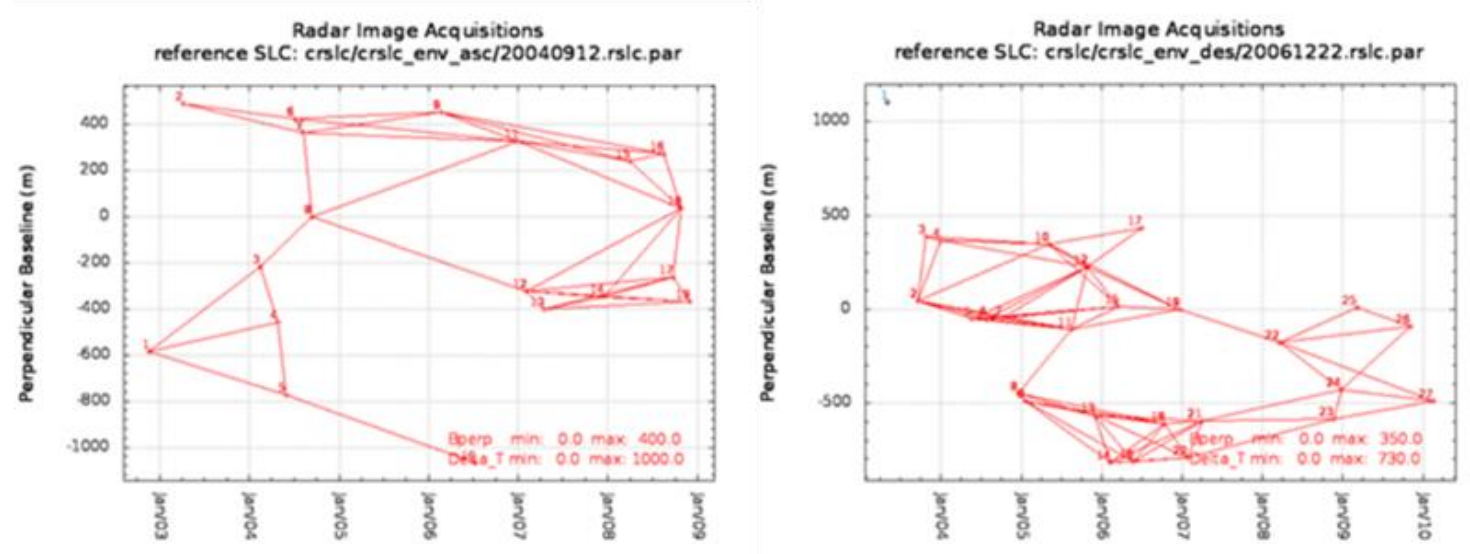

Figure 5: Network of Envisat ascending (on the left) and descending (on the right) for the period 2003-2010

\section{RESULTS}

After the processing with the two Differential Interferometric techniques it is time to visualize the final results for further interpretation. By transforming the interferometric results from range-Doppler coordinates into map geometry, the interferometric analysis results were imported in a GIS environment and elaborated using the Arc Map program in order to display the observation and identification of the results. We should not forget to mention that regarding the stability of the reference points, we assume that they were selected in a stable area but there is a possibility that the points are not absolutely stable.

Therefore the resulting deformation rates are relative measurements to the 'stable' reference point, so when we use the terms of subsidence or uplift is always stated in relative values according to the reference point. One important aspect that affects our results according to Vott which can be seen on figure 6 is the ground movement of the broader area. The arrows indicate relative vertical movement (m) since 4000calBC compared to Trikardo (central Acheloos River delta). As the Akarnanian mass is being separated from central Greece by the rate of $5 \mathrm{~mm} / \mathrm{a}$, rifting distance since 4000 calBC is around $30 \mathrm{~m}$. The curved arrow indicates that Akarnania has been rotating in a clockwise direction since Oligo-Miocene times [28].

Following the processing of the SAR satellite systems, ERS-1\&2 and ENVISAT data, the final maps of surface deformation, over time, were produced for both PSI and SVD techniques, as well as time-series analysis for randomly selected points in the area. PSI method was applied firstly, in order to have a primary evaluation of the deformation in the area of interest. In figures 7 and 8 , the deltaic area of interest comparing to the reference point, presents a maximum subsidence of $-16 \mathrm{~mm} /$ year and a maximum uplift of $14 \mathrm{~mm} /$ year, but in general we can observe that the central mesodeltaic area shows a temporal tension to subsidence as expected due to the geology of the area characterized by the presence of alluvium, and also by the fact that the whole area is surrounded and therefore affected by water. 


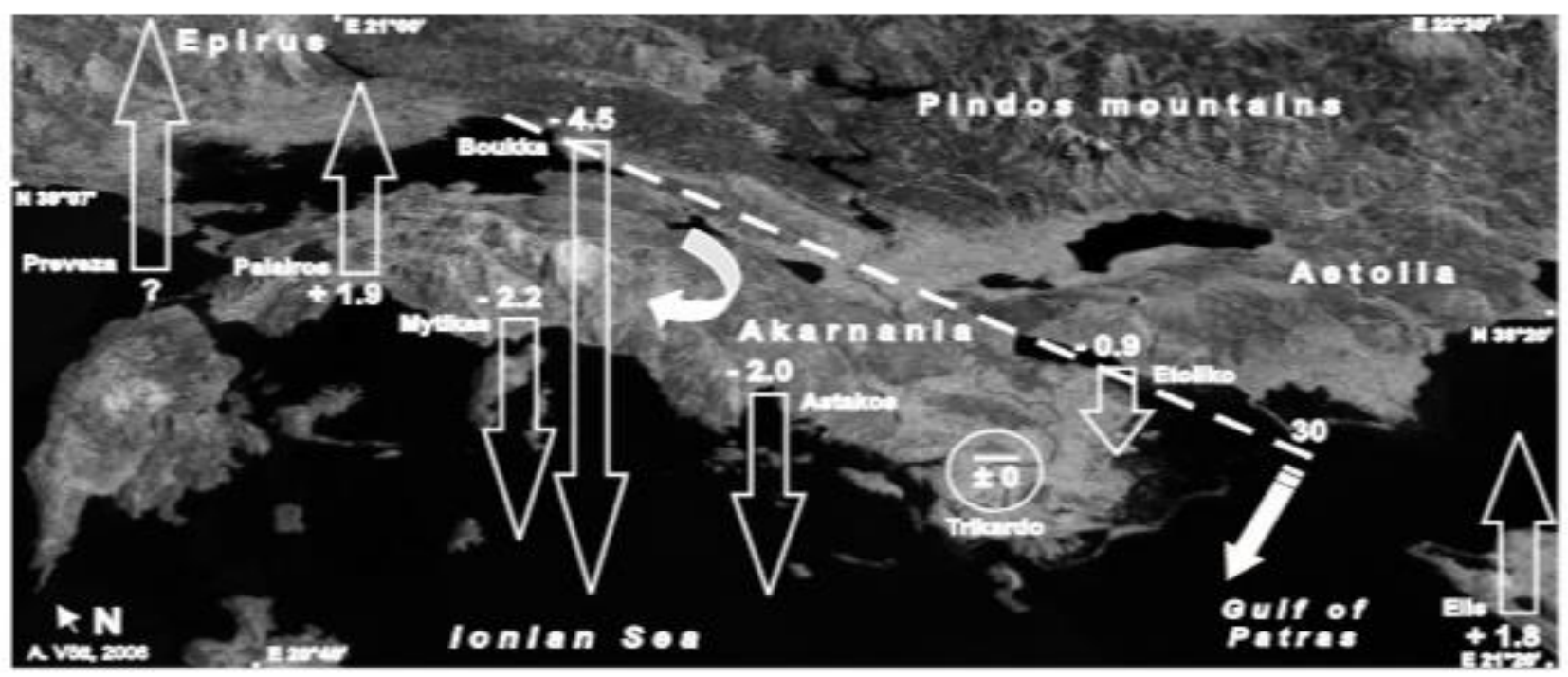

Figure 6: Relative sea level evolution and (neo-)tectonics of northwestern Greece since the mid-Holocene based on sedimentological and geoarchaeological sea level indicators. Map based on NASA World Wind 1.3 picture, vertical exaggeration 3 (source: Vott,2007).

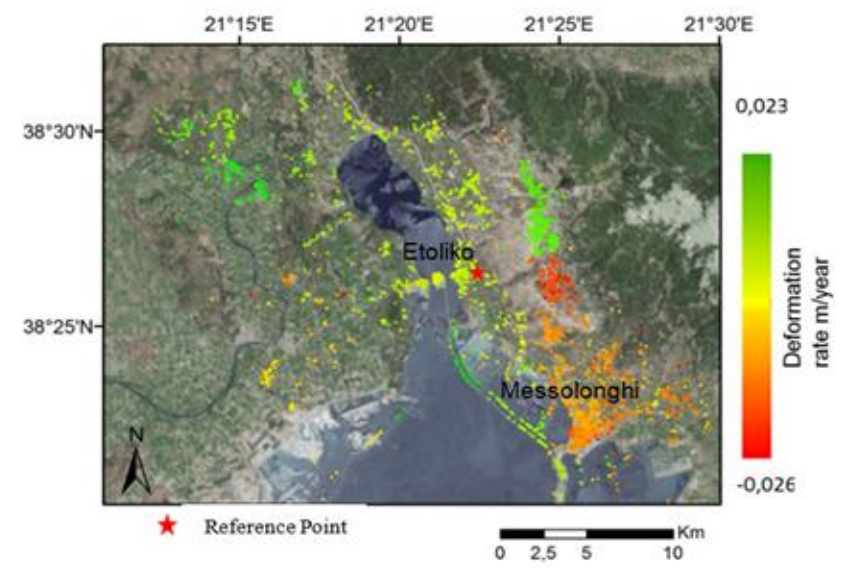

Figure 7: PSI map of the surface deformation rate of Etoliko, for the period 1994-2001, in the LOS direction (satellites ERS$1 \& 2$, ascending track). The red star in the small map represents the reference point.

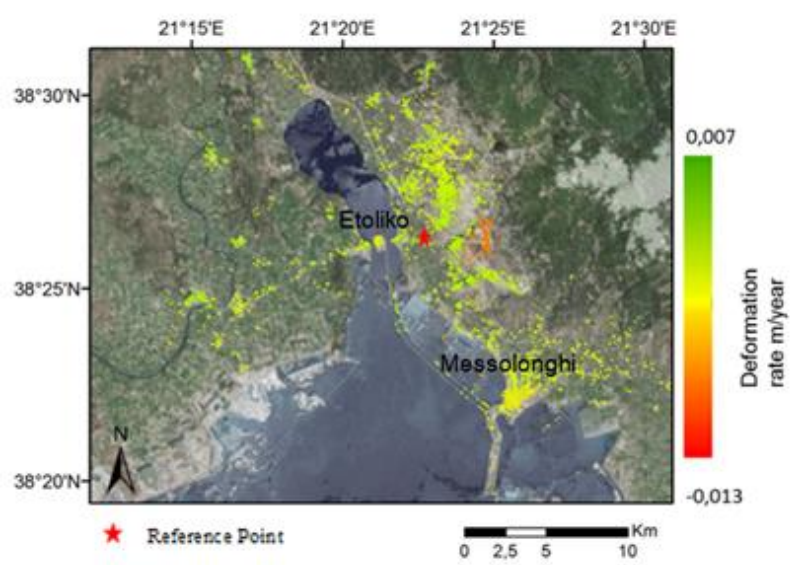

Figure 8: PSI map of the surface deformation rate of Etoliko, for the period 1994-2001, in the LOS direction (satellites ERS-1\&2, descending track). The red star in the small map represents the reference point. 


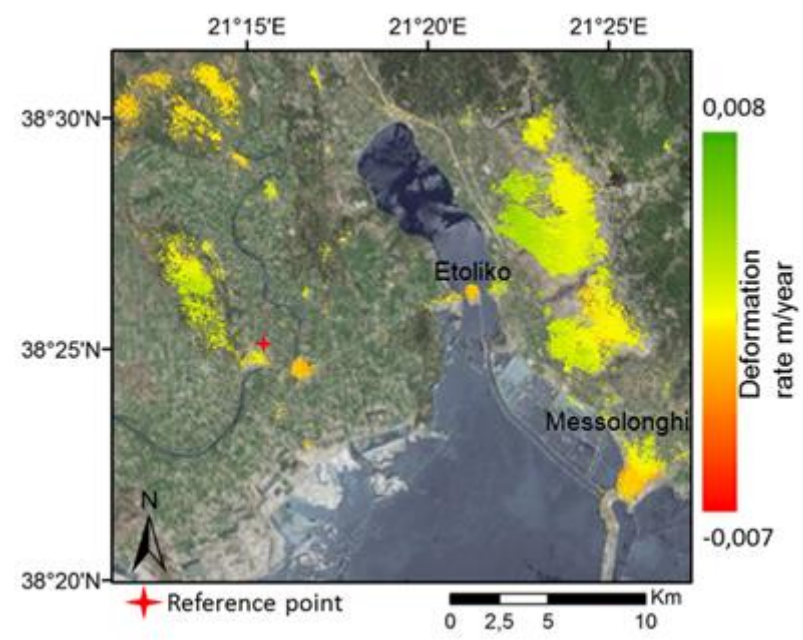

Figure 9: SVD map of the surface deformation rate of Etoliko, for the period 2003-2010, in the LOS direction (satellite ENVISAT, ascending track). The red star in the small map represents the reference point.

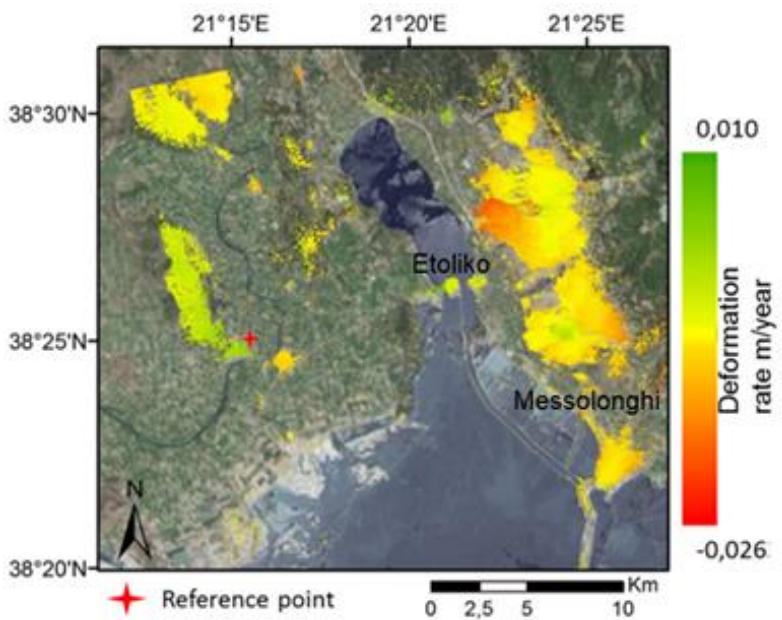

Figure 11: SVD map of the surface deformation rate of Etoliko, for the period 1994-2001 in the LOS direction (satellites ERS1\&2, ascending track). The red star in the small map represents the reference point.

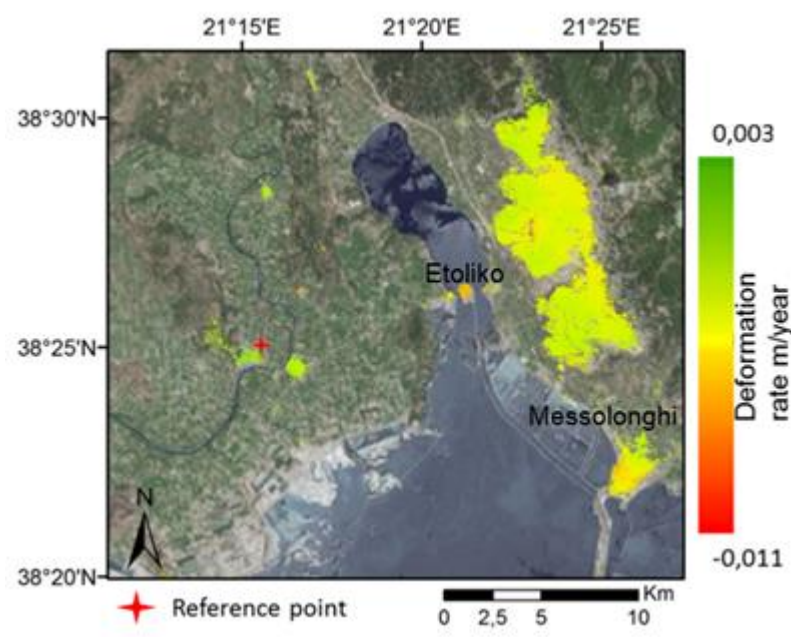

Figure 10: SVD map of the surface deformation rate of Etoliko, for the period 2003-2010, in the LOS direction (satellite ENVISAT, Descending track). The red star in the small map represents the reference point.

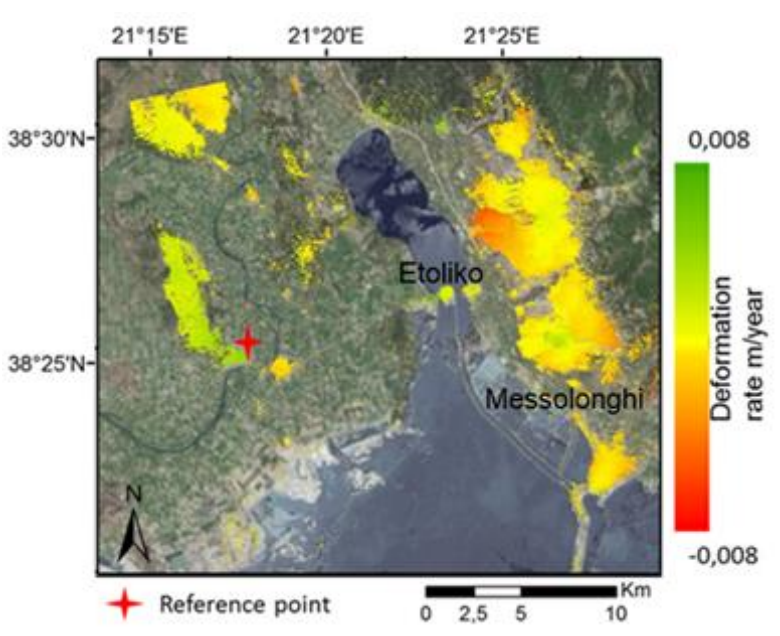

Figure 12: SVD map of the surface deformation rate of Etoliko, for the period 1994-2001 in the LOS direction (satellites ERS1\&2, descending track). The red star in the small map represents the reference point 
Consequently the processing using the PSI technique, we applied the SVD method in order to have a better view of the deformation rate of the area. The SVD maps of the surface deformation rate (Fig.9-12) show also a tension to subsidence and especially at Etoliko and peripherally of Messolonghi. More specifically, for the period 1994-2001 we observe a maximum subsidence rate of around $8 \mathrm{~mm} /$ year in the non-mountainous areas from the satellite data of ERS-1\&2 and $9 \mathrm{~mm} /$ year from Envisat for the period 2002-2010.

Summarizing, multitemporal SAR Interferometry techniques were applied to study the temporal evolution of ground deformation in Etoliko. By the analysis it was allowed to describe the deforming behavior of the area through PSI and SVD approaches, respectively. The results retrieved subsidence specifically close to Etoliko and to the coastal ring of Messolonghi. The high levels over the mountainous areas are due to decorrelation and also due to the faults. In the study area the main cause of ground subsidence seems to be the natural compaction of loose sediments.

\section{CONCLUSIONS}

Sea level change is an aftermath of climate change, and many studies have shown that there are potentially significant impacts for our modern coastal society. During the $21 \mathrm{st}$ century, the average sea level is expected to rise faster worldwide than in the 20th. Relative sea level rise (RSLR; sea level rise adjusted for the sedimentation rate and subsidence) has already been recognized as a serious threat to coastal wetlands, particularly along low-lying sedimentary seacoasts worldwide, where flooding or displacement of coastal wetlands is expected. The current rate of sea level rise, 1-3 mm/y, is very likely to increase the following years due to the aggravating effect of the greenhouse gases and the 'reduction' due to melting of the glaciers. Specifically, a temporal retrospection of our area of interest is showing that the level of progression is estimated to $12.3 \mathrm{~mm} / \mathrm{yr}$ for the period of 8 to $7 \mathrm{ka}$, while for the period 6 to $2.5 \mathrm{ka}$ decreased to $0.2-1.4 \mathrm{~mm} / \mathrm{yr}$, and the $2.5 \mathrm{ka}$ rate increased to $0.7-2.7 \mathrm{~mm} / \mathrm{yr}$ depending on the position [28].

According to a survey conducted by the Greek commission of studying the impacts of climate changes, a similar mean sea level rise rate of $1 \mathrm{~mm} / \mathrm{yr}$ is resulting for the broader area of Akarnania in NW Greece. Considering the increasing tendency of sea level during the last decades and combined with forecasts that the increase will be ranging from 0.2 to 2 meters by 2100 , it is imperative to investigate the coastal areas of high flood risk. A safe risk assessment of a region concerning rising sea level trends, is not only determined by the rate and the high water level range but also by other interrelated factors such as the interaction between tectonics of the area of interest and the eustatism, the dynamic relationship between sea level rising and the change of sediment deposition, as it is well known that if the sediment deposition decreases, as in our case, will increase the transgression of the sea to the coastal area and finally the vulnerability of a region due to rising sea levels that is determined by the topography and the altitude of the coast as well as the composition of the rocks. The latter, determines the rates of erosion as they vary from very high in clay soils to low in limestone and other compact rocks.

On Deltaic coastal areas we have depositions with loose non-cohesive sediments, low absolute altitude and high vulnerability to rising sea levels suggesting that the region of Messolonghi belongs to the high-risk areas. According to Maroukian \& Karymbalis [21], it is estimated that the Evinos delta area that lies below the $50 \mathrm{~cm}$ contour line will be inundated by the sea in the $21^{\text {st }}$ century affecting approximately $12.5 \mathrm{~km}^{2}$ west of the river mouth or $13.6 \%$ of the total delta including Messolonghi area. The major problems of most Greek deltas are associated with the construction of dams in the upper reaches that reduce the sediment supply.

Sea level change is an aftermath of climate change, and many studies have shown that there are potentially significant impacts for our modern coastal society. During the 21st century, the average sea level is expected to rise faster worldwide than in the 20th. Relative sea level rise (RSLR; sea level rise adjusted for the sedimentation rate and subsidence) has already been recognized as a serious threat to coastal wetlands, particularly along low-lying sedimentary seacoasts worldwide, where flooding or displacement of coastal wetlands is expected. The current rate of sea level rise, $1-3 \mathrm{~mm} / \mathrm{y}$, is very likely to increase the following years due to the aggravating effect of the greenhouse gases and the 'reduction' due to melting of the glaciers. Specifically, a temporal retrospection of our area of interest is showing that the level of progression is estimated to $12.3 \mathrm{~mm} / \mathrm{yr}$ for the period of 8 to $7 \mathrm{ka}$, while for the period 6 to $2.5 \mathrm{ka}$ decreased to $0.2-1.4 \mathrm{~mm} / \mathrm{yr}$, and the $2.5 \mathrm{ka}$ rate increased to $0.7-2.7 \mathrm{~mm} / \mathrm{yr}$ depending on the position [29].

According to a survey conducted by the Greek commission of studying the impacts of climate changes [24], a similar mean sea level rise rate of $1 \mathrm{~mm} / \mathrm{yr}$ is resulting for the broader area of Akarnania in NW Greece. Considering the increasing tendency of sea level during the last decades and combined with forecasts that the increase will be ranging from 0.2 to 2 meters by 2100 , it is imperative to investigate the coastal areas of high flood risk. A safe risk assessment of a region concerning rising sea level trends, is not only determined by the rate and the high water level range but also by other interrelated factors such as the interaction between tectonics of the area of interest and the 
eustatism, the dynamic relationship between sea level rising and the change of sediment deposition, as it is well known that if the sediment deposition decreases, as in our case, will increase the transgression of the sea to the coastal area and finally the vulnerability of a region due to rising sea levels that is determined by the topography and the altitude of the coast as well as the composition of the rocks. The latter, determines the rates of erosion as they vary from very high in clay soils to low in limestone and other compact rocks.

On Deltaic coastal areas we have depositions with loose non-cohesive sediments, low absolute altitude and high vulnerability to rising sea levels suggesting that the region of Messolonghi belongs to the high-risk areas. It is estimated that the Evinos delta area that lies below the $50 \mathrm{~cm}$ contour line will be inundated by the sea in the $21^{\text {st }}$ century affecting approximately $12.5 \mathrm{~km}^{2}$ west of the river mouth or $13.6 \%$ of the total delta including Messolonghi area. The major problems of most Greek deltas are associated with the construction of dams in the upper reaches that reduce the sediment supply [21]. This paper can be considered as the beginning of a project approaching through the reliable and precise techniques of interferometry the forecast of an upcoming coastal downgrading and even a socio-economic destruction of the study area. It is obvious that human interventions have modified the physical environment to a great extent. The dam's construction has resulted in a progressive reduction of the fluvial sediments. Diverse geomorphologic and land use changes concerning the coastal plains and the coastal area are also evident in the area. The degradation of this coastal area is accelerated by the salt water's intrusion, the over-exploration of the groundwater and the expansion of the touristic structures. The above in combination to the sea level rise stimulated the necessity of approaching environmental coastal problems by constructing spatial and temporal databases and developing a long-term monitoring mechanism for local and regional planning.

Therefore, it is clear that RSLR forms a threat to the deltaic coastal wetlands, which will require adapted management. Such management should include countermeasures, which could go in three directions, depending on the natural features. The most appropriate measure seems to be the simple use of allocated buffer zones at the edges of the coastal wetlands. Such buffer zones could be further pre-prepared for colonization of new habitats by, e.g., removing the animal species or rare vegetation and preparing a suitable elevation by filling or leveling the existing ground to reach the target microelevations.
On shallow sedimentary coasts, the construction of small artificial islets or mudflats is the simplest solution. The islets should be sited at the desired micro-altitude, depending on the target habitat type. They can be constructed so that they look as natural as possible, especially when fitted properly within the natural bays of lagoons. The newly constructed islets need to be leveled to a previously determined micro-elevation. The less common possibility is applicable only in cases where there is an option to regulate the sea level in areas where the targeted habitats occur, by using artificial sea barriers. The idea is to use dykes to disconnect areas that are currently inundated by the regular influx of seawater.

Subsidence is an important hazard related to the development of urban areas. In order to have a thorough study of the ground, surface deformation demands a continuous and wide spatial-temporal monitoring. By studying the deformation rates obtained by the PS technique, the lithology of the area, the sea level rise rate and any kind of vulnerable human interventions, we can make a reliable prediction for the forthcoming years concerning the risk of flooding, the stability of the area and therefore reduce their impact to humans. We should not forget that a large part of the deltaic area is a protected biotope with many endangered species under protection and therefore the need to take action at this stage will protect the sustainable development of the area in the future. In conclusion, we should mention that future efforts should focus on the quantification of the contribution of each individual deformation fact or through simulation and modeling in order to allow response and mitigation actions. The final aim of this study apart from the ground deformation measurements, is to make a prediction on coastal flooding vulnerability, through the modeling, for the coming decades, which additionally takes into consideration the relative sea level rise.

\section{ACKNOWLEDGMENTS}

This work is in the context of an ongoing $\mathrm{PhD}$ thesis of Gkartzou Evangelia from which all data and results were taken and used for the scope of this paper and also in the frame of a CAT1 ESA project (code: 12482). All the satellite data were provided by the European Space Agency. Therefore, we would like to thank the European Space Agency (ESA) for their support via their projects and the data supply for this research and Harokopio University of Athens for their support and contribution in order to fulfill this paper. 


\section{REFERENCES}

1. Becker, R.H. and Sultan, M., 2009. Land subsidence in the Nile Delta: inferences from radar interferometry. The Holocene, 19, 949-954.

2. Berardino P., Fornaro G., Lanari R. and Sansosti E., 2002. A new algorithm for surface deformation monitoring based on the combination of small baseline DInSAR interferograms, IEEE Trans.Geosci.Remote Sens., vol. 40, pp. 2375-2383.

3. Brooks, M., Clews, J., Melis, N., Underhill, R., 1988. Structural development of Neogene basins in western Greece. Basin Research 1, 129-138.

4. Colesanti C., Ferretti A., Prati C., and Rocca F., 2002. Full exploitation of the ERS archive: Multi data set permanent scatterers analysis, Proc. IGARSS.

5. Dassenakis, M., Krasakopoulou, E., Matzara, B., 1994. Chemical characteristics of Aetoliko lagoon, Greece, after an ecological shock. Marine Pollution Bulletin 28, 427-433.

6. Ferretti, A., C. Prati, and F. Rocca, 1999. Non-uniform motion monitoring using the permanent scatterers technique. Second International Workshop on ERS SAR Interferometry.

7. Ferretti, A., C. Prati and F. Rocca, 2000. Nonlinear subsidence rate estimation using permanent scatterers in differential SAR Interferometry. IEEE Trans. Geoscience Remote Sensing 38(5), pp. 2202-2212.

8. Ferretti A., Prati C., and Rocca F., 2001. Permanent scatterers in SAR interferometry, IEEE Trans. Geosci. Remote Sensing, vol. 39, pp. 8-20.

9. Ferretti, A., F. Novali, R. Burgmann, G. Hilley and C. Prati, 2004. InSAR Permanent Scatterer analysis reveals ups and downs in San Francisco Bay area. EOS, 85(34), pp. 1-3.

10. Gabriel A. K. , Goldstein R. M. , and Zebker H. A., 1989. Mapping small elevation changes over large areas: Differential radar interferometry, J. Geophys. Res., vol. 94.

11. Gianni, A., Kehayias, G., Zacharias, I., 2011. Geomorphology modification and its impact to anoxic lagoons. Ecological Engineering 37 (11), 1869-1877.

12. Gianni, A. and Zacharias, I. 2011. Anoxia, hydrogen sulfide and storm events in Etoliko lagoon, Greece. Proceedings of the 3rd International CEMEPE \& SECOTOX Conference, Skiathos, June 19-24, 2011, ISBN 978-960-6865-43-5, 125- 130.

13. Haenssler, E., et al., 2013. Natural and human induced environmental changes preserved in a Holocene sediment sequence from the Etoliko Lagoon, Greece: New evidence from geochemical proxies. Quaternary International, 308-309, 89-104, doi:10.1016/j.quaint.2012.06.031

14. Hooper, A.J., 2006. Persistent scatterer radar interferometry for crustal deformation studies and modelling of volcanic deformation, Stanford University.

15. Hooper, A., Bekaert, D., Spaans, K. \& Arıkan, M., 2012. Recent advances in SAR interferometry time series analysis for measuring crustal deformation, Tectonophysics.

16. Karapiperis,L., 1974.Rainfall distribution in Greece. Bulletin of the Geological Society of Greece, 11, 1-27.

17. Kokinou, E., Kamberis, E., Vafidis, A., Monopolis, D., Ananiadis, G., Zelilidis, A., 2005. Deep seismic reflection data from offshore western Greece: a new crustal model for the Ionian Sea. Journal of Petroleum Geology 28 (2), 185-202.

18. Kontopoulos, N., Panagos, A., 1980. Morphological analysis of pebbles from the Evinos River. Bulletin of the Geological Society of Greece.

19. Kountoura, K., Zacharias, I, 2009. Study of the refreshment rate of water in the Etoliko lagoon, 9th Greek Symposium of Oceanography \& Fisheries, Proceedings, Volume II, 1235-1240. (In Greek with English abstract).

20. Leonardos, I., Sinis, A. 1997. Fish mass mortality in the Etolikon lagoon, Greece: The role of local geology. Cybium 21, 201-206.

21. Maroukian H., Karymbalis E. 2004. Geomorphic evolution of the fan delta of the Evinos river in western Greece and human impacts in the last 150 years. Z.Geomorph.N.F. 201-217.

22. Massonnet, D.; Rossi, M.; Carmona, C.; Adragna, F.; Peltzer, G.; Feigl, K., and Rabaute T., 1993. The displacement field of the Landers Earthquake mapped by radar interferometry. Nature, 364, 138-142. 
23. Papadas, I.T., Katerinopoulos, L., Gianni, A., Zacharias, I., Deligiannakis, Y., 2009. A theoretical and experimental physicochemical study of sulfur species in the anoxic lagoon of Aitoliko-Greece. Chemosphere 74, 1011-1017.

24. Papanikolaou M., Papanikolaou D., Vasilakis E., 2011. Sea level changes and their impact on coastal areas, Commission of studying the impacts of climate changes, National Bank of Greece, (in Greek with English abstract).

25. Piper, D.J.W., Panagos, A.G., 1981. Growth patterns of the Acheloos and Evinos deltas, western Greece. Sedimentary Geology 28 (2), 111-132.

26. Usai S. 2003. A least squares database approach for SAR interferometric data, IEEETrans. Geosci. RemoteSens, vol.41, no.4, pp.753-760.

27. Vött, A., Schriewer, A., Handel, M., Brückner, H., 2007. Holocene palaeogeographies of the Eastern Acheloos River Delta and the Lagoon of Etoliko (NW Greece). Journal of Coastal Research 23, 1042e1065.

28. Vött, A., 2007. Relative sea level changes and regional tectonic evolution of seven coastal areas in NW Greece since the mid-Holocene. Quaternary Science Reviews 26, 894-919.

29. Weischet, W. \& Endlicher, W., 2000. Regional Climatology, Part 2: The old world, Stuttgart. (In Greek with German abstract).

30. YP.E.CH.O.D.E. / Directorate of Water and Natural Resources.

31. Zebker H. A. and Villasenor J., 1992. Decorrelation in interferometric radar echoes, IEEE Trans. Geosci. Remote Sensing, vol. 30, pp. 950-959.

32. Zebker, H.A., Rosen, P.A., Goldstein, R.M., Gabriel, A., and Werner, C.L., 1994. On the derivation of coseismic displacement-fields using differential radar interferometry - the Landers earthquake. Journal of Geophysical Research-Solid Earth B, 10, 19617-19634. 